\title{
O drama da comunicação pública no Paraná: o caso da RTVE-PR
}

\author{
The drama of public communication in Paraná: the RTVE's case
}

\section{Guilherme Carvalho}

Doutor pela Unesp (2012) e mestre em Sociologia pela Universidade Federal do Paraná (2008). Possui pós-graduação (lato sensu) em Comunicação, Cultura e Arte pela Pontifícia Universidade Católica do Paraná (2013) e graduação em Comunicação Social com habilitação em Jornalismo pela Universidade Estadual de Ponta Grossa (2001). <guilhermegdecarvalho@hotmail.com>

\section{RESUMO}

Apresentamos um estudo do caso da RTVE-PR no qual levantamos dados quantitativos sobre a programação da emissora educativa. Verificamos uma redução da capacidade produtiva da emissora e aumento da reprodução de conteúdos de outras emissoras, como é o caso da TV Cultura que ocupa 29\% da grade de programação da RTVE.Também observamos aspectos qualitativos da programação, nos atendo não às questões técnicas, mas ao conteúdo, onde identificamos o descumprimento do princípio básico do jornalismo de independência editorial nos programas noticiosos, marcada pela ausência de pluralidade de opiniões e pelo reforço às fontes de informação oficiais, sendo o próprio governador um dos mais requisitados.

Palavras-chave: RTVE. Educativa. Comunicação Pública. Paraná.

\begin{abstract}
In this case study of RTVE-PR (Rádio e TV Educativa do Paraná), quantitative data on the programming of the educational broadcaster were collected. A reduction in production capacity of the TV was noted as well as an increase of relay content from other stations, such as TV Cultura, which is occupying 29\% of the RTVE program schedule. Qualitative aspects of programming were observed, not the technical issues, but the content, where it was identified that a breach of the basic principle of editorial independence of journalism in news programs existed, characterized by the absence of a plurality of opinions and a strengthening of the official sources of information; for example, the governor was one of the most requested.
\end{abstract}

Keywords: RTVE-PR. Educativa. Public Communication. Paraná

\section{Introdução}

A Rádio e Televisão Educativa do Paraná (RTVE-PR), com sede em Curitiba, também conhecida atualmente como É-Paraná, é uma emissora estatal criada em 1987. Ao longo de sua existência seu funcionamento foi marcado pelo uso de sua estrutura para atender aos interesses político-partidários, institucionais e pessoais dos governadores que estiveram à frente do estado. No momento em que se verificam tentativas de consolidação de um sistema público de comunicação no país, por meio da criação da TV Brasil, em 2007, práticas como as que vêm sendo exercidas na RTVE-PR ficam mais sujeitas a questionamentos. Principalmente a partir do aprofundamento do debate sobre o papel da mídia pública e sobre sua relevância para a sociedade brasileira. 
Dentre as questões a serem respondidas, está a compreensão sobre o que é mídia pública, procurando entender a noção de "público" em uma sociedade marcada pelo autoritarismo de governos e por uma concepção distorcida sobre o papel do Estado. Nesse cenário, é preciso verificar quais veículos podem ser enquadrados na condição pública. Em sua maior parte, a literatura acadêmica brasileira do campo das Comunicações, por exemplo, tem classificado as emissoras educativas como públicas ou possivelmente públicas. Nossa pesquisa pretende contribuir para este debate partindo de uma pesquisa ainda em andamento e que tem como objeto de estudo a Mídia Pública. Apresentamos um estudo do caso da RTVE no qual levantamos dados quantitativos sobre a programação da emissora, procurando demonstrar que o aparelhamento da emissora para fins particulares anda pari passu com uma redução da sua capacidade produtiva, marcada pelo pouquíssimo tempo dedicado para as produções locais e pela extensa reprodução de conteúdos de outras emissoras, como é o caso da TV Cultura, que ocupa 29\% da grade de programação da RTVE.

Também observamos aspectos qualitativos da programação, nos atendo não às questões técnicas, mas ao conteúdo, onde identificamos o descumprimento do princípio básico do jornalismo de independência editorial nos programas noticiosos, marcada pela ausência de pluralidade de opiniões e pelo reforço às fontes de informação oficiais, sendo o próprio governador um dos mais requisitados. Destaca-se ainda a pouca atenção dada à diversidade da cultura regional e para sua natureza educativa.

Nosso estudo também traz uma análise histórica do desenvolvimento das emissoras educativas do Brasil, com atenção especial à RTVE, para buscar radicalmente os problemas atuais enfrentados pela emissora. Por fim, apontamos nas considerações finais aquilo que identificamos como propostas fundamentais para aproximar a emissora dos fins públicos.

\section{Sistema de comunicação no Brasil e as "educativas"}

No Brasil o sistema de comunicação consolidou-se tardiamente, antes mesmo de uma lógica competitiva de mercado. Sendo assim, o sistema nacionalizado de satélites e cabos, não poderia contar com investimentos privados. "O sistema de redes, condição essencial para o funcionamento da indústria cultural, pressupunha um suporte tecnológico que no Brasil, contrariamente dos Estados Unidos, é resultado de um investimento do Estado. "(Ortiz, 1994, p. 118).

Assim, tem-se naturalizado que o sistema público de comunicação no Brasil deve ser concedido para exploração da iniciativa privada. A partir do ideal 
de Estado-nação, o governo brasileiro deveria promover as condições para que se realizasse uma arena pública de debate - financiando e comprando tecnologia - mas, naquele período (1960-1970), ao mesmo tempo em que exercia um forte controle por meio da censura aos conteúdos exibidos, concedia-se a exploração do sinal para empresários que demonstravam alinhamento ideológico com o governo militar.

Ortiz (1994) demonstra que o governo tinha um forte interesse na expansão dos meios de comunicação brasileiros para que pudesse promover a "integração nacional". A primeira vista, ao receber uma concessão pública para exploração do sinal, qualquer emissora estaria apta a realizar aquilo que o Estado não fez, portanto, deveria atuar como promotora dos interesses públicos e compor um aparente sistema público. Mas a estruturação desse sistema pautase, no entanto, pela demanda do consumo e não pela promoção da cultura local ou do popular. Nessas condições, imperam produções que seguem as razões do mercado, legitimadas pela perspectiva superficialmente política e nacionalista e que formam uma ideia distorcida para os próprios brasileiros do que é cultura e do que é nação (Ortiz, 1994).

A ação do Estado em relação aos meios de comunicação ganhou força com a crise econômica de 1973 marcada pela recessão em países periféricos e o questionamento social que se exercia contra os regimes autoritários. Na emergência de demandas que propunham o fortalecimento das relações entre os países da América Latina, surge uma proposta de "nova ordem mundial da informação e da comunicação" na qual os meios de comunicação de massa deveriam ser encarados como

fundamentais na mobilização da opinião pública para respaldar
as decisões dos dignatários governamentais, principalmente nos
regimes democráticos, onde muitas vezes as campanhas orientadas
por monopólios de difusão massiva podem seduzir multidões
para comportamentos politicamente equivocados, produzindo
repercussões que quase sempre inibem a atuação dos governantes ou
os induzem a retroagir em questões de evidentes interesses nacional
e popular, habilmente manipuladas pelos persuasores profissionais
a serviço de grupos privilegiados ou de interesses externos. (Melo,
1989, p. 16)

A comunicação, portanto, passaria a ser encarada como questão de soberania nacional. Não por acaso, a legislação do Brasil, no que diz respeito à comunicação, passa a impedir investimentos estrangeiros em meios de 
comunicação'. O investimento do Estado deveria ser destinado para infraestrutura e para produção de conteúdo próprio; tornar-se-ia meio para o desenvolvimento cultural, econômico e social dos países.

Não obstante o sistema nacional de comunicação seja operado pela iniciativa privada, como é o caso da radiodifusão e da imprensa, a presença do aparelho estatal é ostensiva e eficiente, operando setores estratégicos que vão das telecomunicações e da informática até as novas tecnologias de fibras óticas, pacotes de dados, antenas para captação de sinais de satélite. (Melo, 1989, p.35).

Os governos militares brasileiros garantiriam na lei a existência de canais de rádio e televisão mantidos pelos estados e municípios. Surgem, então, as emissoras "educativas". A lógica dessas emissoras, criadas a partir do Decreto Lei 236, de 28 de fevereiro de 1967, é o da formação de um contingente populacional com baixa escolaridade que pudesse atuar nas cidades grandes do país que viviam um intenso processo de industrialização (Valente, 2009). Aparentemente, a intenção era preparar o máximo de pessoas possíveis, em menor tempo, para atuar no novo mercado de trabalho que se constituía no país. A iniciativa propunha a substituição da sala de aula para aperfeiçoar alunos e professores. Nesse sentido, não visavam a competição pela audiência. Por outro lado, as "educativas" tinham ainda menor autonomia editorial. Constituíam-se como emissoras dos estados, portanto, estatais, mas com poucas possibilidades de diversificação de conteúdos e pluralidade de opiniões.

A primeira emissora educativa a entrar no ar foi a TV Universitária de Pernambuco, em 1967. Entre 1967 e 1974, surgiram nove emissoras educativas por meio do Decreto-lei 236/67. A lei assinada pelo então presidente Castello Branco, passou a prever no Código Brasileiro de Telecomunicações, criado em 1962, a possibilidade de concessão de canais para União; Estados, Municípios; Universidades; e Fundações, desde que se destinassem "à divulgação de programas educacionais, mediante a transmissão de aulas, conferências, palestras e debates. [...] (E considerando que) A televisão educativa não tem caráter comercial, sendo vedada a transmissão de qualquer propaganda, direta

1 Contraditoriamente, neste mesmo período, em 1965, a TV Globo firmou um contrato de assistência técnica assinada com o grupo norte-americano Time-Life onde recebeu U\$ 5 milhões, no qual previa uma participação nos lucros da emissora brasileira. O acordo foi referendado pelo Governo Federal e a denúncia de inconstitucionalidade arquivada no Congresso Nacional. (Silva, 1985). 
ou indiretamente, bem como o patrocínio dos programas transmitidos, mesmo que nenhuma propaganda seja feita através dos mesmos. " (Decreto, 2015).

Seguindo a política governamental para as rádios e televisões educativas do país, em 1972, o Ministério da Educação (MEC) criou o Programa Nacional de Teleducação (PRONTEL) com o objetivo de coordenar as atividades de teleducação no país. Até o final dos anos 1980, as rádios e televisões educativas contavam com conteúdos inteiramente produzidos sob supervisão do Ministério da Educação, administrado pelo Sistema Nacional de Radiodifusão Educativa (SINRED) (Fradkin, 2015). Com a revisão da legislação a partir dos anos 1990, as emissoras educativas passaram a operar com maior autonomia em relação ao Governo Federal, mas não em relação aos governantes.

As brechas na legislação, ampliadas pela nova conjuntura que beneficiava os interesses privados, fez com que as emissoras educativas do país herdassem o modelo institucional, facilitando o uso para o atendimento de interesses político-partidários, sem que concorressem com os interesses privados. Assim, não era política de Estado constituir emissoras que disputassem audiência com as emissoras privadas. Ao contrário, as estatais atuavam (e ainda atuam em sua maioria) com baixa qualidade de conteúdo e pouca produção própria, relegadas a canais inexpressivos ou com baixíssima audiência.

“O atual modelo descende diretamente do período autoritário, cuja finalidade era assegurar, por meio da imagem eletrônica, a integração nacional no plano do imaginário, deixando de lado o contraditório, a pluralidade, a discordância. " (Bucci, 2015). Ou seja, o cenário atual ainda é frágil em relação às condições para a estruturação de um sistema de comunicação voltado para atender aos interesses públicos. O uso das concessões de TV como "moeda de troca" entre o governo, políticos e empresários, prática conhecida como "coronelismo eletrônico", que garantiu verdadeiros impérios da comunicação como a Rede Globo, ainda é utilizada no país².

2 Fernando Henrique Cardoso (1994-2001) autorizou 357 concessões de TV's educativas sem licitação, parte considerável durante o período em que Pimenta da Veiga (PSDB-MG) ocupou o Ministério das Comunicações. Das concessões que este distribuiu, perto de 100, pelo menos 23 , foram para políticos, a maioria de Minas Gerais. No Governo Lula, durante três anos e meio de seu primeiro mandato, foram aprovadas 110 emissoras educativas - 29 televisões e 81 rádios -, sendo pelo menos sete concessões de televisão e 27 de rádio para fundações ligadas a políticos (Folha, 2015). Diante desse quadro, podemos presumir que parte significativa dessas emissoras está a serviço de interesses particulares e distante de sua finalidade educacional. 


\section{A sina governista da RTVE-PR}

A Rádio e Televisão Educativa do Paraná (RTVE-PR) é transmitida via frequência de rádio AM 630 para Curitiba, cidades do interior próximas à capital e litoral do estado do Paraná, e FM 97,1 para a grande Curitiba. Na televisão o sinal pode ser sintonizado em rede aberta pelo canal 9 VHF, em Curitiba e região. O sinal da emissora também chega a outras regiões do estado por meio de 45 repetidoras e 14 retransmissoras. O sinal também é emitido em formato digital, canal 9.1 e em UHF, canal 36. O conteúdo também pode ser acessado pela internet, em streaming, pelo endereço http://www.e-parana.pr.gov.br/.

A RTVE é uma dentre as 37 geradoras de conteúdo localizadas em território paranaense. $O$ estado ainda conta com 488 retransmissoras que distribuem o sinal das redes para todo o estado, sendo 22 redes de TV em atuação. Em rádio, são 175 emissoras AM e 143 FM. (Donos, 2015).

A Rádio Educativa do Paraná surgiu em 1953, mas só começou a operar em 1955, com transmissão em Curitiba, com sede inicial no Colégio Estadual do Paraná. Em 1992 a emissora passou a se chamar Rádio Educativa e começou a ser transmitida também em frequência FM.

O canal de TV seria criado apenas a partir de 1987, mesmo após alguns anos de concessão pelo governo militar, por meio da promulgação do decreto 839, assinada pelo então governador Álvaro Dias (1986-1991), que promovia uma emenda à Constituição Estadual, na qual criava a Fundação Rádio e Televisão do Paraná.

A Fundação unia os canais derádio e tevê, retirando a rádio da administração da Secretaria Estadual de Comunicação e garantindo orçamento próprio para a emissora. Dentre as funções da RTVE, segundo o estatuto que acompanhava o decreto, estavam a "promoção de atividades educativas e culturais, através do rádio e da televisão. " O artigo $5^{\circ}$ do estatuto prevê a proibição do uso da emissora para fins político-partidários ou para finalidades comerciais, mas permite a doação e repasse de recursos por meio de apoio cultural, seguindo o modelo paulista, já que a manutenção da emissora ligada diretamente ao Estado impediria o repasse de verbas que não fossem exclusivamente estaduais.

A criação da Fundação aparentemente promovia um avanço no aspecto da independência da emissora, seguindo o exemplo da TV Cultura de São Paulo. Mas diferente da emissora paulista, a paranaense previa em sua estrutura organizacional, composta de conselho administrativo, fiscal e de programação, e em sua diretoria executiva, muito poucos mecanismos de participação social ou de quadros especializados. A começar pelo diretor da emissora, que seria 
indicado pelo próprio governador e que deveria estar enquadrado na Secretaria Estadual de Comunicação.

Dos oito membros do Conselho de Administração da emissora, seis deveriam ser provenientes da administração direta do governo. Já, a diretoria executiva tinha ainda menos pluralidade. Ela deveria ser composta pelo diretor presidente, um diretor administrativo-financeiro e um diretor técnico, todos nomeados pelo governador do estado, por proposta do secretário de estado da comunicação social. O mesmo ocorreria com os três membros do conselho fiscal. A lógica também permanecia no Conselho de Programação. Dos oito membros, seis deveriam ser nomeados pelo secretário de comunicação, por meio da indicação de outros secretários do estado.

A organização de uma fundação para prever a produção e transmissão de conteúdos, no entanto, "ficou no papel". A programação praticamente resumiase a retransmissão de conteúdos da TV Cultura e de programas do sistema SINRED do Ministério da Educação.

A TV do Paraná só começaria a produzir algo a partir dos anos 1990 com programas culturais. Em 1991 o então governador Roberto Requião (19911994) assinou o decreto 1.422, que transformava a fundação em autarquia. A nova lei transferia a reponsabilidade de gestão da emissora para a Secretaria de Cultura, dando a entender que a produção se voltaria para uma prática menos institucionalizada. Porém, o regulamento aprovado praticamente reproduzia a estrutura anterior da Fundação, com a diferença de que foram criados departamentos internos, os quais contariam com funcionários indicados diretamente pelo diretor presidente, sendo este, indicado pelo secretário de cultura e nomeado pelo governador. Em essência, a estrutura organizacional e o modelo de gestão permaneciam inalterados. O nome da emissora foi mudado para Canal Paraná e a maior parte da programação era de retransmissão de conteúdos da TV Cultura de São Paulo. A liberdade na produção de conteúdos, no entanto, não poderia nem mesmo ser verificada, uma vez que não havia produção significativa.

Alguns anos depois, na gestão do então governador Jaime Lerner (19952002), a TV passou a se chamar TVE Paraná, sem passar por grandes mudanças 3 .

Em sua segunda gestão (2003-2010), Requião promoveria outra mudança no nome da TV, passando a se chamar Paraná Educativa. Dessa vez a emissora receberia investimentos significativos. Foram contratados 172 funcionários por

3 As mudanças de nome fantasia da RTVE-PR demonstram a ausência de uma política editorial autônoma no canal de TV, uma vez que se muda o nome sempre que muda o governador. A prática tem se repetido sempre que um novo político assume o governo estadual. 
meio de uma parceria com uma fundação ${ }^{4}$ e foram adquiridos equipamentos novos. A emissora finalmente começaria a gerar conteúdo significativo. Em 2007, o Governo do Paraná investiu R\$ 18 milhões na RTVE, o maior montante até então, o que lhe permitiu preencher $44 \%$ de sua grade diária de programação com produção própria. Porém, a falta de independência editorial fez com que a TV ganhasse status de "emissora do governador", por produzir conteúdos de promoção pessoal, o que lhe rendeu processos judiciais.

\begin{abstract}
A Justiça Federal condenou o ex-governador pelos programas e/ ou matérias consideradas ofensivas aos princípios constitucionais invocadas em uma ação popular e na ação civil pública do MPF/ Paraná, como várias edições dos programas 'Governo Hoje', 'Diário do Governo', 'Opinião do Governador', 'Flash Educativa' e 'Pra seu Governo', além de programas sobre partidos políticos e as propagandas institucionais. (MPF, 2015).
\end{abstract}

Todas as terças-feiras pela manhã a emissora transmitia ininterruptamente uma reunião realizada no auditório do Museu Oscar Niemeyer, em Curitiba, que contava com a presença dos membros do primeiro escalão da administração, incluindo o governador e o vice-governador, além de prefeitos e políticos do estado. Na "Escola de Governo", apelidada pejorativamente de "Escolinha do Requião", o governador muitas vezes protagonizava e mediava os debates, o que também lhe rendeu diversos processos, uma vez que ele era acusado de utilizar do horário para fazer ataques a adversários políticos. (Gazeta, 2015).

Nos noticiários da emissora eram evidentes também a parcialidade na seleção de pautas e no tratamento dos fatos. Eram comuns, por exemplo, "sonoras" com o governador com mais de 3 minutos, o que é considerado uma "eternidade" na televisão. Não havia pautas negativas na emissora em relação ao governo estadual, enquanto veículos comerciais do estado apontavam problemas na gestão, o que contribuiu para aprofundar a briga histórica entre Requião e empresas como o jornal Gazeta do Povo e com jornalistas. O próprio governador justificava os embates como resultado dos cortes de orçamento publicitário para os veículos comerciais. Seu antecessor havia destinado R\$ 2,5 bilhões para propaganda nestas empresas, enquanto que ele havia gasto apenas R\$ 203 milhões para os mesmos 8 anos de gestão.

4 A Fundação da Universidade Federal do Paraná (Funpar) contratou os funcionários por meio de um teste seletivo. A contratação previa a cessão de pessoal para a RTVE em troca do pagamento realizado pela emissora utilizando-se de recursos do Governo do Paraná, nos valores de $\mathrm{R} \$ 1,5$ milhão. A forma de contratação foi julgada ilegal posteriormente pela Justiça Federal, obrigando o rompimento do contrato entre RTVE e Funpar. 
De todo modo, a aparição do governador como um interlocutor central nas produções reproduzia o vício autoritário das emissoras educativas.

Aos governos cabe o lugar de fonte de informação - não de mediador da comunicação. Governantes não podem incidir como ordenadores dos processos dos quais resulta, entre outras coisas, a escolha dos próprios governantes". (Bucci, 2015)

A ausência de liberdade editorial na RTVE, durante a gestão de Requião, aparecia também por meio de denúncias de funcionários que apontavam a prática de assédio moral ou ameaças de demissão em caso de não cumprimento dos interesses do governador, práticas que seriam capitaneadas pelo presidente da emissora na época Marcos Antônio Batista Ferreira 5 .

Com a gestão de Beto Richa (2011-2015), a RTVE passaria por uma nova reestruturação em vários aspectos. A começar pelo nome, que passou para É-Paraná, o quinto em menos de 20 anos. A partir de 2012 a emissora voltou a ser fundação, mas dessa vez com a especificação de "pública de administração pública indireta". Ela voltaria a ser responsabilidade da Secretaria de Comunicação, sem passar por transformações relevantes na sua estrutura organizacional. Sobre este tema, o que está em debate atualmente é a lei complementar que institui uma organização social para gerir a emissora. A mudança da forma jurídica da RTVE, inclusive, foi realizada de modo a permitir que se contratassem organizações sociais (OS's) para gerir a emissora.

Pelo projeto, a É-Paraná Comunicação (nome também dado à OS) iniciou seus trabalhos contando com $\mathrm{R} \$$ 1,5 milhões de capital inicial cedidos pelo Governo do Estado. Não há obrigatoriedade de processos seletivos e nem de licitações. Nesse sentido, abre-se a possibilidade de reduzir a fiscalização e o controle sobre o dinheiro público. Nesta modalidade de terceirização, o governo repassa recursos para a "empresa", sem que ela tenha a necessidade de prestar contas à sociedade.

Na lei das OS's (9.637/1998), para garantir que este controle funcione de fato, há um conselho administrativo com percentuais de participação assim definidos: 20 a 40\% de representantes do poder público, 20 a 30\% da sociedade civil, até $10 \%$ de eleitos dentre os associados (quando a personalidade jurídica for associativa), 10 a 30\% de pessoas escolhidas pelo conselho entre pessoas de notório conhecimento e $10 \%$ eleitos conforme o estatuto da entidade. Nesta

5 Estas informações foram obtidas a partir de relatos informais de jornalistas que atuaram na emissora durante este período para este pesquisador. 
composição, fica claro que o governo não poderia, em hipótese nenhuma, ter maioria do conselho de administração. Menos controles legais exigem outros mecanismos de controle social, como um conselho com ampla participação da sociedade. (Messagi, 2013).

Outro ponto queincide diretamentesobrealiberdadeeditorial, diz respeito ao modelo de contratação de funcionários da emissora. Não há dados precisos sobre a quantidade, mas atualmente há um contingente muito pequeno de funcionários estatutários, sendo que nenhum atua diretamente como jornalista. Dos mais de 170 funcionários que haviam na emissora contratados por meio de fundação como celetista, restam menos de 20. A maior parte foi demitida ou os que permanecem são contratados como "cachês". Trata-se de funcionários que cumprema jornada regular, produzem conteúdos, mas não contam com nenhum tipo de formalização de contrato de trabalho. Essa modalidade seria a mesma aplicada para a contratação de artistas que recebem por trabalho executado, mas sem nenhum tipo de garantia. Uma terceira modalidade de contratação são os "comissionados", pessoas nomeadas diretamente pelo governador para atuar na emissora e que ocupam cargos comissionados, também sem maiores garantias de emprego. Com a OS, o que se configura é uma quarta modalidade de contratação que se aproxima muito da terceirização de serviços.

Aprofundou-se, portanto, um ambiente fracionado de trabalho, com diferentes modalidades de contratação que tendem a fragilizar a autonomia e a liberdade editorial dos profissionais e, consequentemente, da emissora. Sabese que a fragilidade dos contratos de trabalho ou subcontratação para todos os tipos de trabalho, juntamente com a desregulamentação do mercado de trabalho, promove a fragmentação e a desorganização da classe trabalhadora, desencadeando um processo de individualização, levando a uma crescente perda de identidade coletiva e de classe (Antunes, 2006).

Em condições inseguras, os funcionários atuam com maior receio de perda de emprego ou de punições e a aceitação de determinadas imposições acaba sendo maior do que em condições mais seguras de emprego. Assim, prevalece a tendência ao silenciamento dos opositores e ausência de questionamentos no ambiente de trabalho. É o que permite um controle sobre o trabalho sem que o mandatário precise exercê-lo com maior rigidez ou de maneira explícita como ocorria na gestão de Roberto Requião. Em caso de descontentamento com o trabalho do jornalista, ele pode ser demitido a qualquer hora, sem ônus financeiro ou jurídico para a organização.

Esta lógica de gestão afeta diretamente a autonomia do trabalhador e, consequentemente, seu desempenho profissional. Ela contribui para o aumento 
quantitativo da produção (o que não ocorreu na RTVE), mas certamente afeta negativamente a qualidade, uma vez que se liga diretamente à liberdade de informação.

Nesse sentido, o que se revela é um controle governamental ainda maior dos conteúdos a serem produzidos pela RTVE. É comum, por exemplo, observar no programa jornalístico daTV conteúdos promocionais que versam sobre ações e obras do governador. Temas presentes na imprensa comercial e que expõem negativamente o governador acabam sendo silenciados ${ }^{6}$. Por outro lado, é comum que parte dos conteúdos exibidos tanto na TV como na rádio estatal tragam como temática assuntos publicados pela Agência Estadual de Notícias, pertencente à Secretaria de Comunicação e que tem como principal atividade a comunicação institucional de cunho promocional ou notícias chamadas de "serviço", que oferecem informações de utilidade pública, geralmente baseadas em ações do governo estadual.

Um dos episódios que marcam este tipo de silêncio é o que ocorreu durante uma greve de professores estaduais realizada no primeiro semestre de 2015. O assunto foi tratado sem isenção, de modo que os representantes dos professores não tinham espaço para dar sua opinião e ouvia-se quase que exclusivamente os membros da administração governamental, isso quando o assunto era tratado durante os dias de greve.

Quando os grevistas que se manifestavam em frente o Palácio do Governo foram dispersados violentamente pela ação da Polícia Militar, no dia 29 de abril, o que se viu foram coberturas bem distintas do que foi exibido em emissoras comerciais. Apesar da repercussão nacional e internacional que o fato ganhou, os acontecimentos e as imagens do dia das agressões foram exibidas de maneira distorcida no jornal noturno da emissora, dando ênfase para a "ameaça" de vândalos que participavam da greve, o que justificaria a ação policial. Em seguida, no dia 4 de maio de 2015, quando deveria ser retransmitido o Jornal da Cultura, como ocorre normalmente, a RTVE intempestivamente exibiu uma apresentação musical durante o horário do telejornal. Naquela noite o Jornal da Cultura exibiria uma cobertura dos acontecimentos que envolviam grevistas e o Governo do Paraná. O fato deixa a entender que a RTVE queria evitar qualquer conteúdo que prejudicasse a imagem do governador, uma vez que o fato era

6 Um programa de rádio que propunha conteúdo jornalístico no ano de 2013 chegou a durar um mês. Segundo relatos informais colhidos por este pesquisador junto a profissionais que trabalhavam na emissora, o programa teria sido extinto quando os jornalistas do programa começaram a apresentar conteúdos que expunham problemas do governo estadual e deixaram de pautar ações promocionais do governador. 
extremamente negativo para suas pretensões políticas. Este é um caso claro de censura exercida na emissora para atender a fins particulares. Verifica-se, portanto, a recorrência da "promiscuidade entre radiodifusão e partidarismo no caso delas, partidarismo governista, o que é um partidarismo com agravante". (Bucci, 2015).

Estes acontecimentos aproximam o modo de Beto Richa e Roberto Requião, adversário políticos, gerirem a RTVE. A diferença é que nos últimos anos, contrariando a tendência anterior, a emissora tem diminuído a quantidade de produções e de exibição de conteúdos próprios. Do ponto de vista qualitativo, durante a gestão de Requião eram visíveis os problemas técnicos na produção, por outro lado, dava-se maior espaço para debates que propunham uma reflexão crítica e maior diversidade de temas por meio de programas como o "Brasil Nação", "Nacionalidade brasileira" e nos conteúdos transmitidos nos telejornais, que possibilitavam a expressão de movimentos sociais e sindicais, por exemplo.

\section{Menos produção, mais retransmissão}

A emissora produz apenas 7 programas fixos, mais o "Interprogramas", o que corresponde a uma média diária de 2 horas de programação própria de segunda a sexta, contando as reprises dos programas próprios exibidos na TV diariamente. Nos sábados essa quantidade aumenta para 4 h30 e, aos domingos para $2 \mathrm{~h} 30$, contando uma reprise.

Dentre os programas produzidos e observados durante o mês de julho de 2015, estão:

- Eureka: programa gravado que se enquadra na proposta de uma emissora educativa, apresentando aulas preparatórias para o vestibular. Exibido às 2 horas da manhã de segunda a sábado, com 1 hora de duração e reprises às 2 horas da manhã e às 16 horas.

- Jornal É-Paraná: programa jornalístico regional ao vivo, exibido de segunda a sexta, às 19h40, com 30 minutos de duração. Este programa conta com uma versão reduzida, o Boletim Agora - É-Paraná, de 10 minutos, exibido de segunda a sexta, às $11 \mathrm{~h} 50$.

-É-Esporte: programa ao vivo com informações do esporte paranaense de $1 \mathrm{~h} 30$, exibido apenas aos domingos, às 20h30. Este programa conta com uma versão reduzida o Boletim É-Esporte, com 10 minutos, exibido de terça a sexta, às 13 horas.

- Marca Paraná: programa gravado sobre iniciativas empreendedoras desenvolvidas no estado. Exibido aos sábados, às 7h30, com 30 minutos de duração. 
- Modão do Brasil: programa gravado de entretenimento sobre música. Apresentado aos sábados, às $17 \mathrm{~h} 30$, com reprise aos domingos às 13 horas com 1 h30 de duração.

-É-Especial: programa gravado com apresentações artísticas locais, exibido aos sábados, às 22 horas, com 1 h30 de duração.

-É-Cultura: programa ao vivo com variedades sobre cultura paranaense. Apresentado de segunda a sexta, às 19h10, com 30 minutos de duração.

- Interprogramas: programetes gravados de um minuto com protagonistas das artes paranaenses, da história e de ações sociais. Exibido diariamente entre intervalos de outros programas.

Destas duas horas diárias é possível considerar como conteúdo jornalístico apenas 1h10, incluindo o programa É-Cultura, que traz elementos noticiosos, mas é mais marcado por ser um programa de variedade e entretenimento. Do contrário, podem ser contabilizados 40 minutos.

- GRÁFICO 1 - Origem da produção exibida na É-Paraná (segunda a sexta)

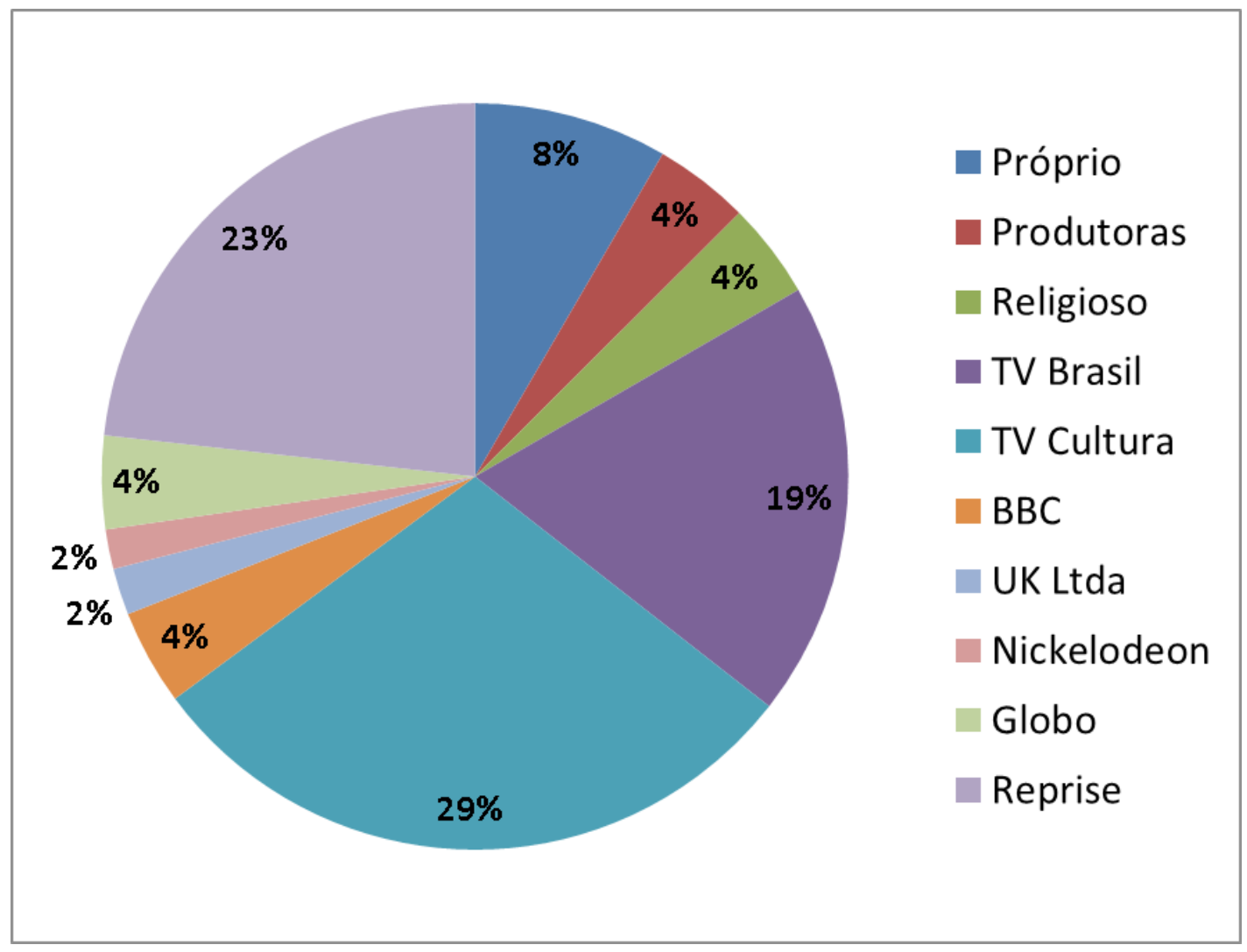

Fonte: Site É-Paraná (2015) 
Do conteúdo exibido em dias do meio de semana, uma grande parte é de reprises, $23 \%$, que incluem, em sua maioria, programas de outras emissoras, sem contar os programas que são exibidos na retransmissão de outras emissoras. $A$ quantidade de produções próprias da RTVE quase é superada até mesmo pela somatória de conteúdos internacionais da BBC, UKLtda e Nickelodeon (7,80\%). O conteúdo educativo fica restrito a retransmissão dos conteúdos da TV Cultura e da Rede Globo por meio dos programas de telecurso, exibido pelas manhãs, e o programa "Eureka", voltado para estudantes de vestibular, este o único na área produzido pela própria É-Paraná. É notável o predomínio de conteúdos da TV Cultura (29\%) e da TV Brasil (18,70\%). Dentre os conteúdos da TV Cultura exibidos na É-Paraná estão os programas infantis como "Quintal da cultura" e "Cocoricó", os noticiosos "Jornal da Cultura" e "Roda Viva", sendo este último um dos principais programas da emissora paulista, e programas de cultura como o "Metrópolis". Da TV Brasil figuram na grade da É-Paraná o "Caminhos da reportagem" e o "Sem censura", entre outros, sendo que as exibições acabam sendo reprisadas ao longo da semana para preencher a grade horária que procura manter a emissora 24 horas no ar.

Cabe ressaltar que a É-Paraná, assim como a TV Cultura, são emissoras públicas que contam com orçamentos e participação na gestão por governos dirigidos pelo PSDB, o que indica uma programação na emissora paranaense que sugere um alinhamento político-editorial com a proposta da emissora paulista que tem recebido críticas por pender para um conteúdo governista (Carta, 2012). Já dos programas da TV Brasil que eram exibidos e que foram excluídos da programação, ressalta-se o "Observatório da imprensa", um programa reconhecidamente de excelência, ao menos na qualidade dos debates, que propunha uma leitura crítica dos meios de comunicação no Brasil. A suspensão realizada recentemente pode reforçar a hipótese do alinhamento ideológico da RTVE-PR ao evitar um conteúdo que aponta críticas ao próprio sistema de comunicação brasileiro.

Comparado ao tempo de exibição de conteúdo próprio, considerando as reprises dessas produções, verifica-se uma redução autoral significativa na RTVE nos últimos anos. Se como Paraná Educativa a emissora de televisão exibia 44\% de conteúdo próprio, como É-Paraná a grade de programação registra pouco mais de $8 \%$, o que representa uma queda de $38 \%$, isso se não descontarmos o tempo de exibição de intervalos na programação onde são exibidos vídeos promocionais sobre ações do governo estadual. 
GRÁFICO 2 - Tipo de conteúdo exibido na É-Paraná por área de interesse (segunda a sexta)

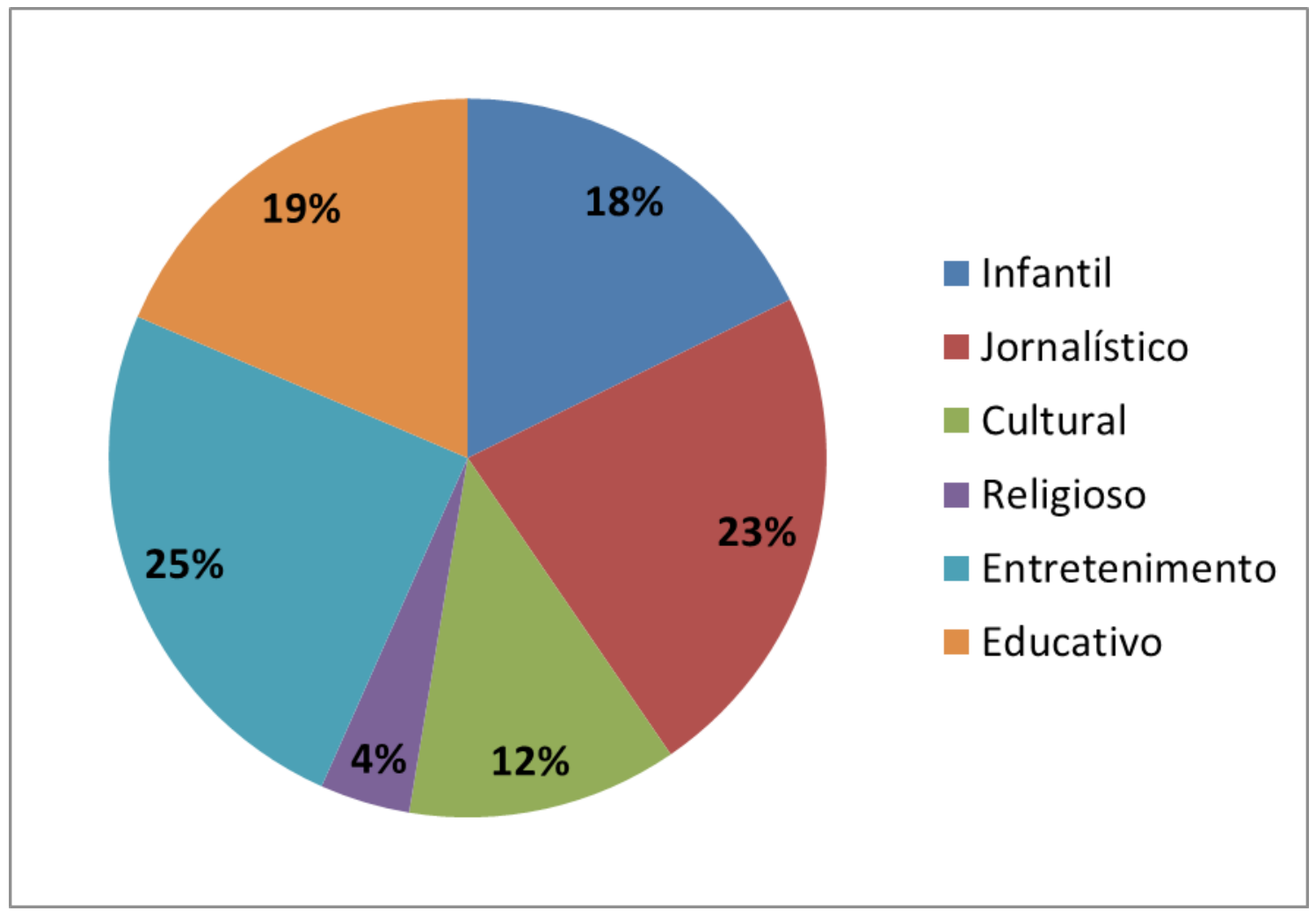

Fonte: Site É-Paraná (2015)

Ao separar os conteúdos por áreas de interesse, observa-se o predomínio de conteúdos jornalísticos e de entretenimento. No gráfico 2 não fazemos distinção entre os conteúdos produzidos ou retransmitidos pela É-Paraná. Assim, a primeira vista, a grade de programação parece acompanhar proporções parecidas com a da TV Brasil e da TV Cultura, uma vez que para cada área, com exceção dos conteúdos religiosos, há uma certa equivalência.

A retransmissão de conteúdos de outras emissoras públicas é bem aceita entre os que se propõem ao debate da mídia pública. A prática estaria relacionada à consolidação de um sistema público que funcionaria como rede nacional e pressupõe a troca ao invés da compra de conteúdos entre as emissoras. No entanto, é observável a pouca diversidade de conteúdos de outras grandes emissoras públicas do país como a Rede Minas, a TVE do Rio Grande do Sul e TV's universitárias que têm uma reconhecida qualidade em suas produções. Há também aspectos relacionados à identidade cultural que acabam ficando de lado, diante da avalanche de conteúdos que estão mais ligados a outras 
realidades, como é o caso do Jornal da Cultura, que tem uma proposta editorial mais voltada para o telespectador paulista.

Com uma grade de exibição de conteúdos próprios reduzida, a realidade da RTVE-PR aproxima-se da de outras emissoras educativas do país.

\begin{abstract}
Programas jornalísticos e culturais são predominantes nas 1.965 horas mensais produzidas por todas as 19 emissoras. Na imensa maioria dos casos, a programação das associadas da ABEPEC tem vocação generalista - o menu contempla programas infantis, telejornalismo, transmissões esportivas, musicais, games, filmes, variedades, documentários, produtos culturais e paradidáticos. A teledramaturgia, por sua vez, aparece esparsa e sazonalmente, tanto na programação infantil quanto adulta. Há de se situar como forma abrandada da linha generalista, a TV E do Ceará, que opera como TV Escola durante 55 horas semanais. (Diagnóstico, 2006, pp. 46-47)
\end{abstract}

Em alguns casos, a produção própria cai a zero. A TV Cultura e a TV Brasil ocupam entre $80 \%$ a $95 \%$ da grade de programação com material gerado pelas duas junto a emissoras associadas. A média de conteúdos próprios produzidos pelas emissoras educativas estaria em torno de $23 \%$. A redução da capacidade de produção de conteúdos da RTVE-PR contrasta paradoxalmente com o aumento dos investimentos na emissora nos últimos anos ${ }^{7}$. Com mais dinheiro, seria lógico pensar que a emissora teria melhores condições de produzir mais e com melhor qualidade. Porém, para preencher sua grade de programação a É-Paraná precisa recorrer à retransmissão de conteúdos de outras emissoras e reprises de conteúdos, reduzindo a diversificação e a promoção cultural regional.

7 Em 2010, a emissora recebeu do governo estadual, durante a gestão de Roberto Requião, o montante de $R \$ 17.508 .960$, sendo que o gasto com pessoal ficou em cerca de $R \$ 8,5$ milhões (LOA, 2010).

Em 2011, quando assumiu o governo estadual, Beto Richa elevou os valores do repasse para a RTVE para cerca de R\$ 27 milhões (LOA, 2011). Já em 2012, na Secretaria de Comunicação Social, o montante do tesouro do estado foi de $R \$ 23.679 .700$, mais $R \$ 101$ mil. (LOA, 2012). Este valor corresponde a $30 \%$ do orçamento total da Secretaria naquele ano. Dentre os maiores gastos da emissora estavam a "difusão da programação cultural da É-Paraná", que exigiu R $\$ 158$ mil, $\mathrm{R} \$ 22,3$ milhões com a "gestão administrativa" (pagamento de pessoal), o que corresponde a $94 \%$ do valor anual da emissora, e R $\$ 1$ milhão com "gestão de serviços" (despesas com energia elétrica, água e esgoto, telefonia, processamento e transmissão de dados).

Os valores surpreendem uma vez a capacidade produtiva da RTVE foi reduzida, mesmo diante do aumento do gasto com pessoal, o que, pela lógica, deveria resultar justamente no contrário. 
Ao estudar a questão em programas telejornalísticos de comunicação pública da TV Brasil e da TV Cultura, Coutinho e outros (2015) identifica características que distinguem a produção destas emissoras em relação à mídia comercial. A pesquisa procura elementos que denotem qualidade para a produção, baseada em critérios previstos no "I Fórum de TV's públicas" realizado em 2007. Seriam elementos de qualidade questões como independência na linha editorial em relação a governos e partidos, aprofundamento dos temas, maior tempo de reportagem, notícias de interesse publico, isenção de relatos, tratamento ao telespectador como cidadão e não consumidor, além do estímulo à participação, conteúdos que não são abordados na mídia comercial, ênfase às questões de direitos humanos, representação de diferentes grupos identitários destacando aspectos regionais e pluralidade de opiniões. Sobre este último considera-se que:

A perspectiva de pluralidade de vozes no telejornalismo público orientaria a constituição dos programas jornalísticos em uma emissora pública como espaço para o exercício do direito à comunicação, para além do direito à informação de qualidade, aferida segundo parâmetros de excelência. (Coutinho, 2005, p.30)

Ao compararmos, então, a programação atual da RTVE-PR às emissoras comerciais, verifica-se que raramente algum desses requisitos é atendido. A exceção são as notícias de interesse público, mas que, em geral, estão atreladas a algum tipo de campanha institucional ou promocional do governo estadual. É comum, por exemplo, que as fontes de informação das notícias produzidas pela emissora sejam provenientes de meios oficiais, isto é, gestores do próprio governo que compõem o dito primeiro e o segundo escalão da administração. O próprio governador Beto Richa tem sua opinião reproduzida quase que diariamente no tele e no radiojornal da emissora, sem que versões contrárias sejam expostas. Contra-argumentos, contestações, conflitos praticamente inexistem na produção jornalística, eliminando a pluralidade de opiniões. Ao restringir, portanto, o direito de acesso a outras opiniões, a capacidade de reflexão e de crítica sobre os diferentes temas da sociedade acabam sendo empobrecidas em decorrência do privilégio dado a versão unicamente oficial.

O contrário só aparece quando se trata de reportagens que apontem problemas na administração municipal de Curitiba, dirigida pelo prefeito Gustavo Fruet (PDT), e ao governo federal, dirigido por Dilma Rousseff (PT), ambos adversários políticos de Beto Richa. 
Ao evitar o contraditório ao governo estadual, a RTVE que deveria ser a expressão máxima do debate público e da mediação das relações de poder na sociedade paranaense, reforça uma relação de autoritarismo e de aparelhamento da máquina pública para atendimento de interesses particulares, uma relação típica do que no Brasil ficou conhecido como "coronelismo político". O problema decorre da incompreensão da sociedade sobre o papel que uma emissora pública de comunicação deve desempenhar. Esse, no entanto, não é um problema exclusivamente dos paranaenses, como se observou anteriormente. As práticas governamentais sobre os meios de comunicação, sejam públicos ou privados, carregam um histórico de transgressão do direito à informação no Brasil.

\section{Considerações finais ou propostas fundamentais para uma emissora pública}

A transformação da RTVE-PR em uma emissora realmente pública, ou seja, orientada exclusivamente pelo interesse público, implica em uma independência editorial que permita à emissora produzir e transmitir conteúdos que promovam uma reflexão crítica de seus ouvintes e telespectadores. Nesse sentido, é necessária uma reorganização da estrutura, que consolide bases para que se exercite uma autonomia de gestão e de produção e uma participação popular, seguindo o exemplo de outras emissoras onde tem se configurado um outro modelo, como no caso da TV Brasil e da TV Cultura, que apresentam uma programação mais plural.

A questão da qualidade da emissora não deve, portanto, ser observada simplesmente por aspectos técnicos, ainda que em alguns casos as produções da RTVE mereçam revisões nesse aspecto. Mas nos referimos à restrição do direito de acesso à informação e aos conteúdos próprios voltados para o campo cultural e educativo que foram reduzidos a quase zero, descumprindo o propósito de uma emissora pública, conforme Coutinho (2015), ou ao seu papel legal.

As condições atuais da emissora, bem como os efeitos disso sobre o público que assiste ou ouve o conteúdo da RTVE carecem de pesquisas. A priori, podemos dizer que em um cenário de baixa qualidade, compreendendo aqui a independência editorial, a premissa do interesse público, a diversificação dos conteúdos, a pluralidade de opiniões e a regionalização da programação como questões qualitativas, reforça-se um sentimento de descrédito e de irrelevância para a emissora, um problema presente e que tem acompanhado a RTVE desde o seu surgimento. 
Além da revisão do sistema de gestão a partir da previsão de conselhos mais plurais, outra medida fundamental nesse sentido seria a garantia de condições seguras para os contratos de trabalho, de modo que os funcionários da emissora não fiquem reféns das questões conjunturais para que possam atuar sem o receio de punições ou perda de emprego em caso de não atender certos interesses particulares de partidos ou governantes.

Por fim, uma outra medida fundamental é a transformação da natureza jurídica da RTVE e sua desvinculação de estruturas institucionais que tendem a compreender a emissora como "correia de transmissão" de interesses de governos. O distanciamento, no entanto, deve vir acompanhado da garantia legal de repasse de recursos públicos para a emissora de modo que possa assegurar uma produção com qualidade sem depender de dinheiro da iniciativa privada ou de outras fontes de arrecadação que exijam a submissão da sua linha editorial aos interesses particulares.

\section{Referências}

ANTUNES, R. Os sentidos do trabalho: ensaio sobre a afirmação e a negação do trabalho. 8. ed. São Paulo: Boitempo, 2006.

$\mathrm{BUCCl}$, Eugênio. A razão de ser das emissoras públicas na democracia. Disponível em: $\quad<$ http://interessenacional.uol.com.br/index.php/edicoes-revista/a-razaode-ser-das-emissoras-publicas-na-democracia/>. Acesso em: 10 jul. 2015.

CARTA, Mino. A TV Cultura não é pública. Ela é tucana. Disponível em: < htttp://www. conversaafiada.com.br/pig/2012/03/16/mino-tv-cultura-nao-e-publica-etucana/>. Acesso em 30 mar. 2012.

COUTINHO, lluska (org.) A informação na TV pública. Florianópolis: Insular, 2015.

DECRETO-Lei 236. Disponível em: <http://www.planalto.gov.br/ccivil 03/Decreto-Lei/ Del0236.htm>. Acesso em: 13 jul. 2015.

GAZETA do Povo. Transmissão da "Escolinha do Requião" é suspensa. < $\underline{\text { http:// }}$ www.gazetadopovo.com.br/vida-e-cidadania/transmissao-da-escolinha-dorequiao-e-suspensa-a3689emb5q9gk7bib21jtz32m>. Acesso em: 10 jul. 2015.

LOA. Lei de Orçamentária Anual do Paraná. Curitiba: Alep, 2010

LOA. Lei de Orçamentária Anual do Paraná. Curitiba: Alep, 2012

MELO, José Marques (org.). Comunicação na América Latina: desenvolvimento e crise. Campinas: Papirus, 1989. 
MESSAGI, Mário. E-Paraná Comunicação: pior que OS's e com demissões em massa. Disponível em: <http://sindijorpr.org.br/artigos-interna/5/artigos/4872/eparana-comunicacao--pior-que-os\%C2\%B4s-e-com-demissoes-em-massa> . Acesso em: 16 out. 2013.

MPF. Roberto Requião é condenado pela Justiça Federal em ação do MPF. Disponível em: $\quad<$ http://www.prpr.mpf.mp.br/news/roberto-requiao-e-condenado-pelajustica-federal-em-acao-do-mpf >. Acesso em 15 jul. 2015.

ORTIZ, Renato. A moderna tradição brasileira. São Paulo: Brasiliense, 1994.

SITE E-PARANÁ. Programação. Disponível em: <http://www.e-parana.pr.gov.br/ modules/programacao/programacao.php?veiculo=0 >. Acesso em: 3-20 jul. 2015.

SILVA, Carlos Eduardo Lins. Muito além do jardim botânico: um estudo sobre a audiência do jornal Nacional entre trabalhadores. São Paulo: Summus, 1985.

VALENTE, Jonas. Concepções e abordagens conceituais sobre sistema público de comunicação. In: Sistemas públicos de comunicação no mundo: experiências de doze países e o caso brasileiro. São Paulo: Paulus, Intervozes, 2009. 